\title{
Association of serum TNF-a, IL-8 and free light chain with HLA-DR B alleles expression in pulmonary and extra-pulmonary sarcoidosis
}

\author{
Esmaeil Mortaz ${ }^{1,2,3,4}$, Hale Abdoli Sereshki ${ }^{3}$, Atefeh Abedini ${ }^{5^{*}}$, Arda Kiani ${ }^{5}$, Mehdi Mirsaeidii, Dina Soroush ${ }^{3}$,
} Johan Garssen ${ }^{2}$, Aliakbar Velayati ${ }^{3}$, Frank A Redegeld ${ }^{2}$ and lan M Adcock ${ }^{4}$

\begin{abstract}
Background: Sarcoidosis is a systemic disease of unknown etiology characterized histologically by the observation of non-caseating granulomas and several immunological abnormalities. Sarcoidosis is a multi-organ disorder which involves formation of granulomas in many tissues including the lungs (pulmonary) and others such as skin, bone, heart (extra pulmonary). Associations between human leukocyte antigens (HLA), the encoded cell surface receptor (HLA-DR) and sarcoidosis have been reported in several studies. Several HLA-DR alleles have been described as potential risk factors for sarcoidosis in distinct ethnic groups however evidence for a relationship between HLA-DR alleles and pulmonary and extra-pulmonary sarcoidosis (EPS) is still scarce. Although the etiology of the disease remains unclear, infectious and environmental factors have been postulated. Inflammatory cytokines and chemokines may play important roles in the pathogenesis of sarcoidosis and serum free light chain (FLC) numbers have been implicated in several immunologic disorders.
\end{abstract}

Purpose of the study: The aim of the present study was to investigate HLA associations with serum cytokines and FLC in Iranian patients with pulmonary $(n=86)$ and EPS $(n=46)$.

Results: We found that among the $16 \mathrm{HLA}$ DRB alleles only *7 and * 12 were different in sarcoidosis patients. The levels of TNF-a and IL-8 in pulmonary sarcoidosis patients were higher than in EPS $(P<0.05)$ whereas the levels of FLC subunits in EPS were higher than in pulmonary sarcoidosis.

Conclusion: This data may suggests a link between HLA-DRB *12 and sarcoidosis in Iranian population.

Keywords: Sarcoidosis, HLA-DR, TNF-a, IL-8

\section{Introduction}

Sarcoidosis (MIM 181000) is a systemic granulomatous disease that was originally described over 100 years ago [1]. Although any organ system can be involved, pulmonary involvement occurs in about $90 \%$ of cases although skin, eye, cardiac, liver and neurologic manifestations are not uncommon. The disorder has been described in all races and in every continent except Antarctica [2]. While many cases may undergo spontaneous regression, onethird of cases are persistent and require therapy. An

\footnotetext{
* Correspondence: Dr.abedini110@gmail.com

${ }^{5}$ Chronic Respiratory Diseases Research Center, National Research Institute of Tuberculosis and Lung Diseases, Shahid Beheshti University of Medical Sciences, Tehran, Iran

Full list of author information is available at the end of the article
}

infectious agent has been suspected as the cause of this disorder but a non-specific etiology has also been identified $[1,3]$.

The inflammatory response in sarcoidosis is characterized by the accumulation of CD4 $\mathrm{T}$ cells at the sites of disease activity [4]. A Th1 type response has been suspected because of the granulomatous response and the observation of increased levels of IL-2 and IFN gamma in the disease [5]. These $\mathrm{T}$ cells expressed oligoclonal $\mathrm{T}$ cell receptors consistent with a response to an environmental antigen [6]. These findings strongly supported an excessive inflammatory reaction or hypersensitivity to some innocuous agent. The utility of corticosteroids and other anti-inflammatory drugs in the treatment of this disorder also support this concept. 
A genetic susceptibility to sarcoidosis has been supported by studies demonstrating familial clustering [7]. First-degree relatives have a higher prevalence of disease and familial clustering has been observed in different populations but most noticeably in African Americans [8]. Polymorphisms in a number of candidate genes have been associated with sarcoidosis [9-14].

The clinical presentation of sarcoidosis depends on epidemiological factors such as age, gender and race; the duration of the disease and the anatomical sites involved [15-18]. Although the lungs are involved in most patients with sarcoidosis, recognition of extra-pulmonary sarcoidosis (EPS) requires awareness of the organs most commonly affected, such as the skin and the eyes, and vigilance for the most dangerous manifestations, such as cardiac and neurologic involvement. EPS may be lifethreatening and may also affect the therapeutic approach taken [19].

There is evidence that patients with pulmonary plus EPS have greater severity of symptoms, restrictions in daily activities and quality of life and impairment of health status comparing to the patients with isolated pulmonary sarcoidosis [20]. However, there are limited clinical and laboratory parameters that differentiate patients with pulmonary sarcoidosis alone from those patients with accompanying EPS.

Cytokines have been implicated in the pathogenesis of sarcoidosis for many years. In particular, the role of IL- 8 and TNF- $\alpha$ have been frequently studied [21-25]. Granulomas in the skin and lungs have recently been described as a source of nuclear IL-33 expression and its expression was strongly correlated with the presence of systemic disease [26]. The data indicated that the local inflammatory milieu within each sarcoidal granuloma is critical for IL-33 expression and that IL-33 expression represents a novel biomarker for systemic involvement of the disease [26].

Serological and molecular analyses of HLA molecules have also been investigated in sarcoidosis. Unfortunately, because of the limitations of study design and techniques used to identify HLA molecules (low resolution molecular typing) it has not been possible to reach a consensus on the importance of HLA molecules in sarcoidosis [27]. Currently, there is no information on organ involvement and frequency of EPS involvement in sarcoidosis patients from Middle East.

Immunoglobulin free light chains (FLC) can exert various biological functions: enzymatic activity, binding to intracellular and extracellular proteins and cellular interactions [28]. Different inflammatory disorders and autoimmune diseases are accompanied by elevated FLC levels in different body fluids [29-34] and the increased FLC concentrations correlate with relapses of disease and enhanced activity of the immune system [35-39]. Thus, in current study we aimed to investigate whether patients with pulmonary sarcoidosis differ from those with EPS in routinely assessed clinical and laboratory data including HLA-DRB polymorphisms, FLC and TNF- $\alpha$ and IL-8 expression.

\section{Materials and methods \\ Patients}

Sarcoidosis patients $(\mathrm{n}=86)$ were recruited from Sarcoidosis clinic center from Massih Daneshvari Hospital between January 2012 and August 2014, Tehran-Iran. All patients met the diagnostic criteria for sarcoidosis established by the American Thoracic Society consensus panel [40]. The inclusion criteria consisted of clinical and pathological data and patients with a differential diagnosis were excluded.

Specific phenotypes of sarcoidosis were defined according to the ACCESS group [41]. A summary of the various extra-pulmonary sites in the clinical cohort is shown in Tables 1 and 2. Exclusion criteria were individuals with fungal disease active tuberculosis or who were taking antituberculosis therapy. Pathology slides were reviewed by a trained pathologist at each clinical center and the medical records, chest radiographs and study tests were reviewed by the principal investigator at each clinical center. An interviewer-administered questionnaire was also undertaken by each participant.

\section{Controls}

95 controls were recruited as described previously [42] by random digit dialing (RDD) methods from the same geographic region as the clinical cases. Controls were matched to cases on the basis of age (within 5 years), gender and self-reported race and ethnicity. Controls were excluded if they reported a history of sarcoidosis or

\section{Table 1 Characteristics of the study population}

\begin{tabular}{ll}
\hline Organ & $\%$ (number) \\
\hline Pulmonary involvement & $63(86)$ \\
Extrapulmonary involvement & $40(46)$ \\
Skin & $30(34)$ \\
Endocrine & $9,3(8)$ \\
Extrathoracic lymph node & $11.6(11)$ \\
Eyes & $9(10)$ \\
Liver & $10.5(9)$ \\
Spleen & $10.5(9)$ \\
Cardiac & $7(6)$ \\
Ear, nose, and throat & $7(6)$ \\
Muscles & $14(12)$ \\
Bone/joints & $9.3(8)$ \\
Kidney & $4.6(4)$ \\
\hline
\end{tabular}


Table 2 Demographic of patients in subjected groups

\begin{tabular}{|c|c|c|c|}
\hline \multirow[t]{2}{*}{ Variable } & \multicolumn{2}{|l|}{ Sarcoidosis } & \multirow{2}{*}{$\begin{array}{l}\text { Healthy } \\
\text { control } \\
\text { subjects }\end{array}$} \\
\hline & Pulmonary & Extrapulmonary & \\
\hline Number of subjects & 86 & 46 & 95 \\
\hline Age (mean $\pm \mathrm{SD}$ ) years & $39.4 \pm 8.8$ & $38.96 \pm 9.4$ & $37.7 \pm 9.3$ \\
\hline \multicolumn{4}{|l|}{ Sex } \\
\hline Female & 58.8 & 26.3 & 55 \\
\hline Male & 27.2 & 20.7 & 45 \\
\hline \multicolumn{4}{|l|}{ Radiologic stage } \\
\hline \multicolumn{4}{|l|}{ I } \\
\hline$\|$ & 2 & 4 & $\mathrm{~N} / \mathrm{A}$ \\
\hline III & 66 & 19 & $\mathrm{~N} / \mathrm{A}$ \\
\hline IV & 18 & 22 & $\mathrm{~N} / \mathrm{A}$ \\
\hline \multicolumn{4}{|l|}{ Current treatment } \\
\hline Steroid (number) & 65 & 32 & $\mathrm{~N} / \mathrm{A}$ \\
\hline Methotrexate (number) & 21 & 14 & $\mathrm{~N} / \mathrm{A}$ \\
\hline CRP (ng/ml) & $13.3 \pm 14.6$ & $10.1 \pm 3$ & $\mathrm{~N} / \mathrm{A}$ \\
\hline Hypercalcemia (number) & 46 & 13 & $\mathrm{~N} / \mathrm{A}$ \\
\hline Anemia (number) & 21 & 3 & $\mathrm{~N} / \mathrm{A}$ \\
\hline
\end{tabular}

medical conditions that made the determination of sarcoidosis uncertain (e.g. granulomatous hepatitis or idiopathic uveitis). This study was approved by the Ethics Committee of Massih Daneshvari Hospital, Medical College of Shahid Beheshti University and the Institutional Review Board of National Research Institute Tuberculosis and Lung Diseases (NRITLD) Medical Center and was in compliance with the national legislation and Declaration of Helsinki guidelines.

\section{DNA preparation}

Heparinized blood was collected from each case and control at the time of the interview and was sent by overnight courier to the DNA core laboratory for DNA isolation and purification. High molecular weight DNA was isolated from non-coagulated blood by detergent lysis and organic extraction. Purified DNA samples were diluted to a standard concentration $(1 \mu \mathrm{g} / \mathrm{ml})$ in 10 mMTris, $5 \mathrm{mM}$ EDTA buffer and being frozen at $-70^{\circ} \mathrm{C}$ until analysed. DNA integrity and concentrations were monitored using agarose gel electrophoresis and ethidium bromide staining.

\section{Determination of HLA-DRB alleles}

Determination of HLA-DR B1 subtypes was performed using single specific primer-polymerase chain reaction (SSP-PCR) methods (Texas BioGene, USA).The PCR products were loaded onto a $0.5 \%$ agarose gel and the expression of various alleles was visualized by Gel DOC (Bio-RAD, USA). HLA-DR subtypes were calculated according to the manufacturer's instructions. Only primers that completely matched the target sequences result in amplified products under the controlled PCR conditions and the presence of an amplified DNA fragment is a positive indication of the existence of an allele-specific sequence in the genomic DNA.

\section{Quantification of serum cytokines}

IL-8 concentrations were quantified by ELISA (BD Biosciences Pharmingen, Breda, The Netherlands) according to the manufacturer's instructions. Serum levels of TNF- $\alpha$, IL- 6 and IL- $1 \beta$ were also measured by ELISA kits (Invitrogen, USA) according to the manufacturer's instructions.

\section{Measurement of FLC in serum}

Total lambda $(\lambda)$ and kappa ( $\mathrm{k}$ ) FLC concentrations were determined in all sera using an ELISA adapted from Abe et al. as described previously [43,44]. In brief, plates were coated $\mathrm{o} / \mathrm{n}$ with goat anti-mouse IgG (M4280; Sigma, Zwijndrecht, The Netherlands) at $4^{\circ} \mathrm{C}$, blocked (1 $\mathrm{h}$; RT) before incubation with mouse anti-human $\kappa$ or $\lambda$ Ig-FLC MAb's (obtained from Dr. A. Solomon, Tennessee, USA). After incubation with different dilutions of samples and standards (The Binding Site, Birmingham, $\mathrm{UK})$, plates were incubated with HRP-labeled goat $\mathrm{F}\left(\mathrm{ab}^{\prime}\right)$ 2-anti-human $\lambda$ and $\mathrm{k}$ light chain antibodies (AHI1804 andAHI1904, respectively; Biosource, Life Technologies Europe, Bleiswijk, The Netherlands). TMB was used as substrate. At least three data points within the linear range of the standard curve were used per sample to estimate the FLC concentration.

\section{Statistical analysis}

All conditions were performed in triplicate, and all experiments were repeated up to five times. Results are presented as mean \pm S.E.M. Data were compared using the unpaired 2-tailed, student's $t$-test using GraphPad Prism (version 2.01). Results were considered statistically significant when $\mathrm{p}<0.05$.

\section{Results}

Analysis of the HLADR *B1-16 alleles in the study population

To determine whether there were different allelic distributions in sarcoidosis patients and their matched controls, a global test was performed for each allele group of the 16 DRB *1-16 alleles detected. A representative gel of the results is shown in Figure 1. The data was quantified and allelic frequencies are given in Tables 3 and 4 . The $H L A-D R B 1 * 7$ allele was significantly different between pulmonary (17.7\%) and EPS subjects (4.1\%, $\mathrm{p}<0.05$ ) (Table 3). In addition there was a significant difference in the frequency of the HLA-DRB1 "12 allele 


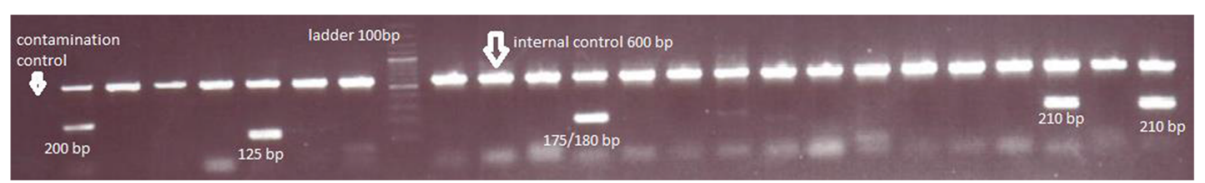

Figure 1 Representative gel electrophoresis of PCR products. Detection of allele-specific amplified bands in $0.5 \%$ agarose gel by single specific primer-polymerase chain reaction (SSP-PCR).The gel is representative of the gel analysis of all DNA samples. Cont $=$ control subject, EPS = extra-pulmonary sarcoidosis patient and PS = pulmonary sarcoidosis patient. The product size in bp refers to the amplification of a selective allele in that sample. The internal control represents a conserved region of the house keeping gene (provided in kit) and serves as an indication of the integrity of PCR reaction.

between pulmonary (1\%) and EPS patients $(8.2 \%, \mathrm{p}<0.05)$ (Table 3 ) and this allele was also identified as a risk factor for sarcoidosis. The distributions of the HLA-DRB1 alleles were significantly different between the pulmonary sarcoidosis patients and the EPS patients $(\mathrm{P}<0.001$, Table 4$)$.

\section{Levels of IL-8, IL-6and IL-1 $\beta$ in serum of pulmonary and} extra-pulmonary sarcoidosis

The serum levels of IL-8 were significantly increased in both pulmonary and EPS patients compared with control subjects (Figure 2, upper panel). There was no significant difference between the two sarcoidosis groups however. The serum levels of IL- 6 and IL-1 $\beta$ were not significantly different between patients with pulmonary sarcoidosis or EPS or between healthy controls (data not shown).

Levels of TNF- $a$ in pulmonary higher than extrapulmonary sarcoidosis

Serum TNF- $\alpha$ levels in pulmonary sarcoidosis patients were significantly increased compared with control subjects, but no increase was observed in patients with EPS (Figure 2, lower panel).

Table 3 Frequency of HLA-DRB1 in control and sarcoidosis patients

\begin{tabular}{|c|c|c|c|}
\hline DR B1* & $\%$ patients $(n=86)$ & $\%$ controls $(n=95)$ & P-value \\
\hline${ }^{*} 01$ & $6.1 \%$ & $10.4 \%$ & 0.54 \\
\hline${ }^{*} 03$ & $18.4 \%$ & $14.6 \%$ & 0.55 \\
\hline${ }^{*} 04$ & $10.2 \%$ & $18.4 \%$ & 0.18 \\
\hline${ }^{*} 07$ & $4.1 \%$ & $17.7 \%$ & 0.02 \\
\hline${ }^{*} 08$ & 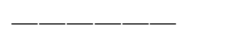 & $5.2 \%$ & 0.16 \\
\hline *09 & - - - - & $1 \%$ & 1.0 \\
\hline$* 10$ & $12.2 \%$ & $5.2 \%$ & 0.18 \\
\hline$* 11$ & $36.6 \%$ & $36.7 \%$ & 0.87 \\
\hline$* 12$ & $8.2 \%$ & $1 \%$ & 0.04 \\
\hline$* 13$ & $22.4 \%$ & $22.9 \%$ & 0.95 \\
\hline *14 & $20.2 \%$ & $12.5 \%$ & 0.21 \\
\hline$* 15$ & $32.7 \%$ & $18.8 \%$ & 0.06 \\
\hline${ }^{*} 16$ & $8.2 \%$ & $14.6 \%$ & 0.27 \\
\hline
\end{tabular}

Free light chain levels in the serum of pulmonary sarcoidosis and EPS patients

There was a significant increase in serum $\mathrm{k}$ (Figure 3, right panel) and $\lambda$ (Figure 3 , left panel) FLC in patients with EPS compared with control patients. There was no increase in either $\mathrm{k}$ or $\lambda$ FLC levels in patients with pulmonary sarcoidosis as compared to control subjects. The increase in $\lambda$ FLC in EPS was also significantly greater than that in pulmonary sarcoidosis patients.

\section{Discussion}

In this study we investigated whether HLA-DRB * subtyping could distinguish between sarcoidosis patients with pulmonary or extra-pulmonary involvement. We found that among the 16 HLA DRB alleles only *7 and *12 were different between sarcoidosis patients and controls with *12 being identified as a risk factor for sarcoidosis [45]. This study shows also a significant difference between the overall distribution of the HLA-DRB1 alleles between pulmonary sarcoidosis patients and patients with EPS. We further demonstrated increased levels of serum TNF- $\alpha$ and IL- 8 in pulmonary sarcoidosis patients, while TNF- $\alpha$ was not increased in EPS subjects. Serum levels of FLCs

Table 4 Frequency of HLA-DRB1 in pulmonary and extra pulmonary sarcoidosis

\begin{tabular}{lll}
\hline HLA-DRB1* & Pulmonary & Extra-pulmonary \\
\hline${ }^{* 01}$ & 4 & - \\
${ }^{*} 03$ & 4 & 2 \\
${ }^{*} 04$ & 3 & - \\
${ }^{* 07}$ & 2 & - \\
${ }^{* 08}$ & - & - \\
${ }^{* 09}$ & - & - \\
${ }^{* 10}$ & 3 & 2 \\
${ }^{* 11}$ & 19 & 4 \\
${ }^{* 12}$ & 3 & - \\
${ }^{* 13}$ & 8 & 2 \\
${ }^{* 14}$ & 8 & - \\
${ }^{* 15}$ & 15 & 4 \\
${ }^{* 16}$ & 2 & 2 \\
\hline
\end{tabular}




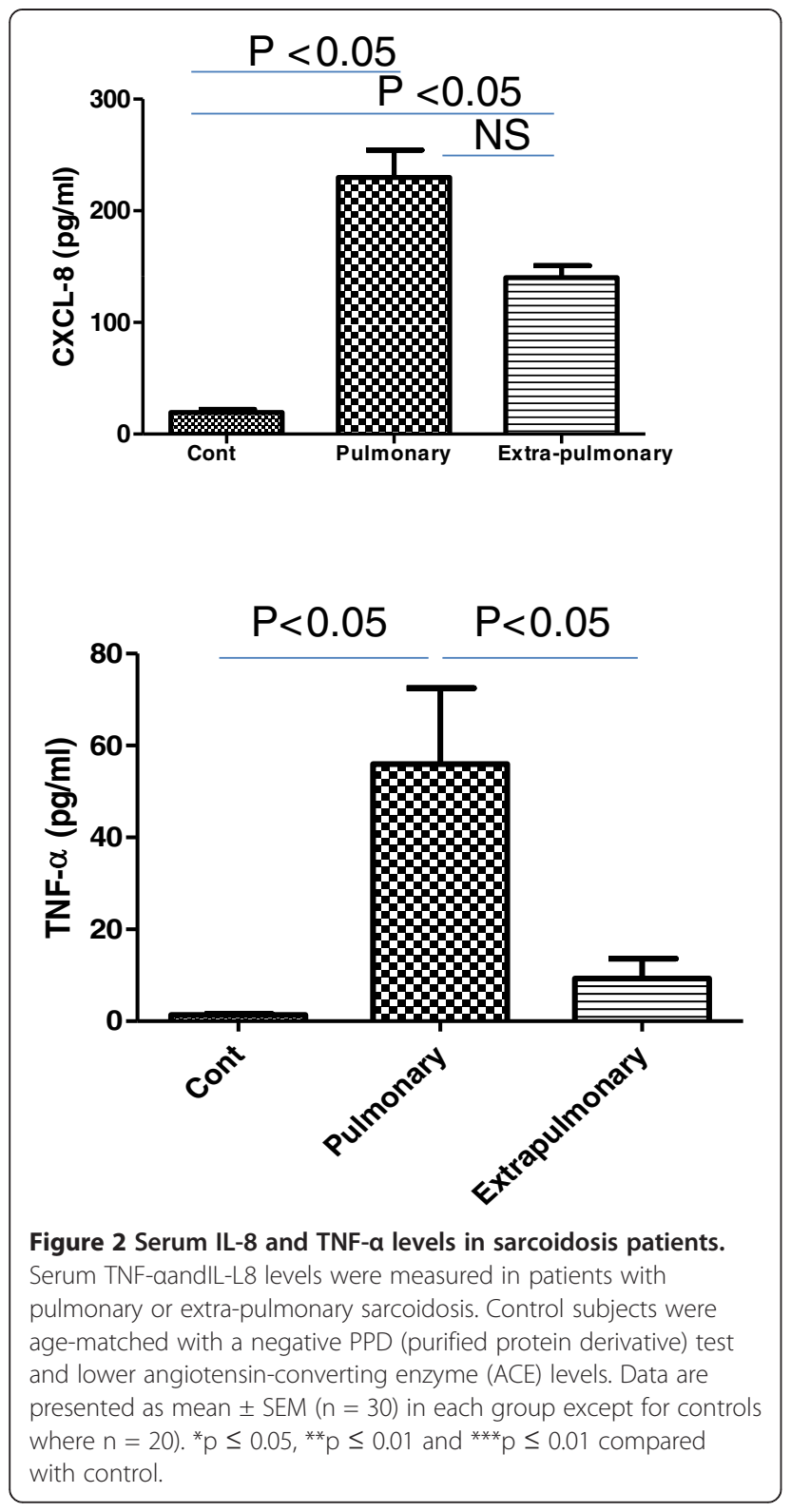

were higher in EPS patients and not in pulmonary sarcoidosis. This is the first report showing different expression of HLA-DRB sub-types in pulmonary and EPS. The differential presence of pro-inflammatory markers such as TNF- $\alpha$, IL-8, and FLCs may point to a different pathology in the two sarcoidosis subgroups.

Among the alleles tested, only the expression of the "07 and "12 were significantly altered in sarcoidosis with the frequency of " 07 being decreased whereas that of "12 being increased compared with control subjects. It has previously been reported that the presence of the HLADR B *7 allele is related to a good disease prognosis $[46,47]$. Indeed, our patients with this genotype had good response to treatment. In contrast, in Swedish sarcoidosis patients the levels of DHL-DR *7 are increased
[48]. The frequency of HLA-DR B*012 expression has been extensively reviewed [49] and the HLA DR-B*12 frequency is similar in our population as in three other populations from UK, Holland and Japan.

Variations in HLA-DRs associations have also been reported in sarcoidosis patients across different ethnic groups. For example, although the frequency of HLADRw52 was significantly greater in Japanese sarcoidosis patients compared to control groups there was no significant association with HLA-B antigens [50]. In addition, an association between sarcoidosis and HLA-DR5 has been reported in a German cohort of sarcoidosis patients [51]. This emphasizes that there may be ethnic differences in the expression of these specific alleles in sarcoidosis patients and that there is a need to further analyze other HLA class I and II subtypes in Iranian sarcoidosis patients in future studies.

We also report enhanced levels of serum IL-8 in both pulmonary sarcoidosis and EPS patients. To our knowledge there has only been one previous report showing elevated IL-8 levels in sarcoidosis [52]. Car and colleagues showed that IL-8 levels were significantly increased in bronchoalveolar fluid (BAL) of patients with sarcoidosis [53]. IL-8 is rapidly produced by different cell types upon exposure to inflammatory stimuli such as TNF- $\alpha$ and LPS and is considered as one of the most potent neutrophil chemoattractants in human tissue [54-57]. Recent evidence using blood transcriptomic analysis [58] indicates that neutrophilia is present in sarcoidosis patients as well as in other interferon- and immune-related diseases linked to activation of pattern recognition receptors and to anti-bacterial and -viral defenses. The clinical importance of the increased levels of IL-8 in serum and BAL needs further testing.

In addition, serum levels of TNF- $\alpha$ were increased in patients with pulmonary sarcoidosis but not in those with EPS. TNF- $\alpha$ is a pro-inflammatory cytokine previously shown to play a critical role in the pathogenesis of Th1 responses and to be elevated in sarcoidosis patients [58]. TNF- $\alpha$ plays a significant role in antigen-stimulated, cell-mediated immune responses and in the development of non-caseating granulomas in a variety of diseases [59]. In sarcoidosis, alveolar macrophage-derived TNF- $\alpha$ participates in the induction and maintenance of granulomas [60] and high levels of TNF- $\alpha$ released from alveolar macrophages seem to correlate with disease progression [61]. In addition, BAL levels of TNF- $\alpha$ and IL- 6 are significantly higher in pulmonary sarcoidosis patients compared with control subjects [62]. Thus, we were able to recapitulate the BAL findings in relation to TNF- $\alpha$ in blood in our study.

However, the failure to demonstrate increased serum levels of IL-1 $\beta$ and IL- 6 in sarcoidosis requires further investigation. This may result from the involvement of 

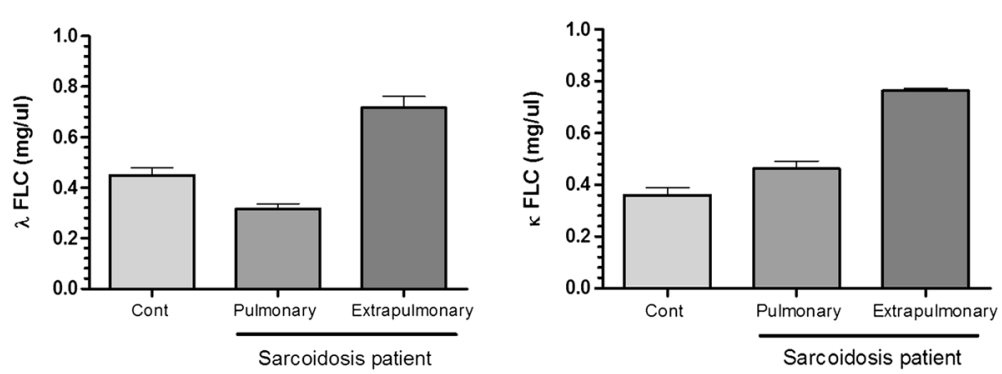

Figure 3 The levels of free light chain (FLC) kand $\boldsymbol{\lambda}$ in serum of sarcoidosis patients. Free light chain concentrations in serum of sarcoidosis patients. Kappa ( $K$, right panel) and lambda ( $\lambda$, left panel) FLC concentrations are significantly highly increased in the serum of extra-pulmonary sarcoidosis patients compared with patients with pulmonary sarcoidosis and in control subjects. Results are expressed as means \pm SEM of results from 20 control subjects, 30 pulmonary sarcoidosis subjects and 30 extra-pulmonary sarcoidosis patients.

distinct cell types present in blood and BAL since these cytokines and chemokines are all stimulated by the same stimuli involving NF-kB activation [63]. This may also explain the differences in TNF- $\alpha$ expression observed between pulmonary sarcoidosis and EPS.

We also report elevated levels of both $\kappa$ and $\lambda$ FLC in the serum of EPS patients but not patients with pulmonary sarcoidosis. Sarcoidosis is known as a T cell mediated disease but B-cells may play a role in its pathogenesis particularly in chronic disease [64,65]. It is possible that the release of free light chains is from a distinct set of inflammatory cells in the blood of these patients. A growing body of evidence suggests that serum FLCs could be useful biomarkers in several immunological conditions as they reflect B-cell polyclonal activation including active sarcoidosis [65]. Serum FLC levels are also elevated in lupus [66], rheumatoid arthritis and Sjögren syndrome $[37,45,67]$ where they are also associated with the active state of the disease. Serum FLCs have also recently been reported as biomarkers of systemic sclerosis activity and severity $[68,69]$. In the current study the expression of $\mathrm{k}$ and $\lambda$ FLCs was greater in EPS patients compared with patients with pulmonary sarcoidosis. The differential expression of $\kappa$ and $\lambda$ FLCs in EPS and pulmonary sarcoidosis requires confirmation in other cohorts and its functional importance needs to be further established. However, we speculate that B cells may play a more significant role in EPS compared to pulmonary sarcoidosis and that these patients may benefit from B cell-directed therapy.

In conclusion, we report for the first time that HLA DRB *12 may be indicative of sarcoidosis and that there is a differential HLA DRB allele usage between patients with EPS and pulmonary sarcoidosis. There were also differences in serum inflammatory markers between these two groups of sarcoidosis patients with patients with pulmonary sarcoidosis having greater levels of TNF- $\alpha$ and IL-8 than EPS and control subjects. Conversely, the expression of $\kappa$ and $\lambda$ FLCs was greater in EPS patients compared with pulmonary sarcoidosis patients. Overall, we report a link between HLA-DRB sub-types and inflammation in Iranian patients with sarcoidosis. We suggest that these novel markers should be readily incorporated into current laboratory analysis as they are relatively cheap and rapid, taking less than $48 \mathrm{~h}$, and provide additional parameters for the differentiation of subtypes of sarcoidosis.

\section{Competing interests}

The authors declare that they have no competing interests.

\section{Authors' contributions}

EM and HA carried out the molecular genetic studies, participated in and drafted the manuscript. AA carried out the writing whole paper and AK was leader of team. MM, JG and IA participated in the designing the experiments and performed the statistical analysis. DS participated in the cytokines analysis. All authors read and approved the final manuscript.

\section{Acknowledgements}

IMA is supported by the MRC (G1001367/1) and the Wellcome Trust (093080/Z/10/Z). Research by IMA is also supported by the NIHR Respiratory Disease Biomedical Research Unit at the Royal Brompton NHS Foundation Trust and Imperial College London. EM is supported by an ERS Long Term Fellowship (LTRF 2013-2052).

\section{Author details}

${ }^{1}$ Department of Immunology, Faculty of Medicine, Shahid Beheshti University of Medical Sciences, Tehran, Iran. ${ }^{2}$ Division of Pharmacology, Utrecht Institute for Pharmaceutical Sciences, Faculty of Sciences, Utrecht University, Utrecht, the Netherlands. ${ }^{3}$ Clinical Tuberculosis and Epidemiology Research Center, National Research and Institute of Tuberculosis and Lung Diseases (NRITLD), Shahid Beheshti University of Medical Sciences, Tehran, Iran. ${ }^{4}$ Airways Disease Section, National Heart and Lung Institute, Imperial College London, London, UK. ${ }^{5}$ Chronic Respiratory Diseases Research Center, National Research Institute of Tuberculosis and Lung Diseases, Shahid Beheshti University of Medical Sciences, Tehran, Iran. ${ }^{6}$ Division of Pulmonary, Critical Care, Sleep and Allergy, University of Illinois at Chicago, Chicago, Illinois, USA.

Received: 11 January 2015 Accepted: 3 March 2015

Published online: 19 March 2015

\section{References}

1. Newman LS, Rose CS, Maier LA. Medical progress: sarcoidosis. N Engl J Med. 1997;336:1224-34.

2. Mortaz E, Masjedi MR, Tabarsi P, Pourabdollah M, Adcock IM. Immunopathology of sarcoidosis. Iran J Allergy Asthma Immunol. 2014;13 (5):300-6.

3. Siltzbach LE, James DG, Neville E, Turiaf J, Battesti JP, Sharma OP, et al. Course and prognosis of sarcoidosis around the world. Am J Med. 1974;57:847-52. 
4. Hunninghake GW, Crystal RG. Pulmonary sarcoidosis: a disorder mediated by excess helper T-lymphocyte activity at sites of disease activity. N Engl J Med. 1981;305:429-34.

5. Pinkston P, Bitterman PB, Crystal RG. Spontaneous release of interleukin-2 by lung T lymphocytes in active pulmonary sarcoidosis. N Engl J Med. 1983;308:793-800.

6. Moller DR. Involvement of T cells and alterations in T cell receptors in sarcoidosis. Semin Respir Infect. 1998;13:174-83.

7. Rybicki BA, Kirkey KL, Major M, Maliarik MJ, Popovich JJ, Chase GA, et al. The familial risk-ratio of sarcoidosis in African-American sibs and parents. Am J Epidemiol. 2001;153:188-93.

8. Rybicki BA, lannuzzi MC, Frederick MM, Thompson BW, Rossman MD, Bresnitz EA, et al. Familial aggregation of sarcoidosis: a case-control etiologic study of sarcoidosis (ACCESS). Am J Respir Crit Care Med. 2001;164:1885-9.

9. Arbustini E, Grasso M, Leo G, Tinelli C, Fasani R, Diegoli M, et al. Polymorphisms of angiotensin-convertingenzyme gene in sarcoidosis. Am J Respir Crit Care Med. 1996;153:851-4.

10. Ishihara M, Naruse T, Ohno S, Kawata H, Mizuki N, Yamagata N, et al. Analysis of HLA-DM polymorphisms in sarcoidosis. Hum Immunol. 1996:49:144-6.

11. Rybicki BA, Maliarik MJ, Malvitz E, Sheffer RG, Major M, Popovich JJ, et al. The influence of T cell receptor and cytokine genes on sarcoidosis susceptibility in African Americans. Hum Immunol. 1999;60:867-74

12. Pandey JP, Frederick M. TNF-alpha, IL1-beta, and immunoglobulin (GM and KM) gene polymorphisms in sarcoidosis. Hum Immunol. 2002;63:485-91.

13. Sharma SK, Balamurugan A, Pandey RM, Saha PK, Mehra NK. Human leukocyte antigen-DR alleles influence the clinical course of pulmonary sarcoidosis in Asian Indians. Am J Respir Cell Mol Biol. 2003;29(2):225-31.

14. Zorzetto M, Bombieri C, Ferrarotti I, Medaglia S, Agostini C, Tinelli C, et al Complement receptor 1 gene polymorphisms in sarcoidosis. Am J Respir Cell Mol Biol. 2002;27:17-23.

15. lannuzzi MC, Rybicki BA, Teirstein AS. Sarcoidosis. N Engl J Med. 2007:357:2153-65.

16. Baughman RP, Teirstein AS, Judson MA, Rossman MD, Yeager Jr H, Bresnitz EA, et al. Clinical characteristics of patients in a case control study of sarcoidosis. Am J Respir Crit Care Med. 2001;164(10 Pt 1):1885-9.

17. Dempsey OJ, Paterson EW, Kerr KM, Denison AR. Sarcoidosis. BMJ. 2009;339:b3206

18. lannuzzi MC, Fontana JR. Sarcoidosis: clinical presentation, immunopathogenesis, and therapeutics. JAMA. 2011;305:391-9.

19. Rao DA, Dellaripa PF. Extrapulmonary manifestations of sarcoidosis. Rheum Dis Clin N Am. 2013;39:277-97.

20. Gvozdenovic BS, Mihailovic-Vucinic V, llic-Dudvarski A, Zugic V, Judson MA. Differences in symptom severity and health status impairment between patients with pulmonary and pulmonary plus extrapulmonary sarcoidosis. Respir Med. 2008;102:1636-42.

21. Nagata K, Maruyama K, Uno K, Shinomiya K, Yoneda K, Hamuro J, et al. Simultaneous analysis of multiple cytokines in the vitreous of patients with sarcoid uveitis. Invest Ophthalmol Vis Sci. 2012;53(7):3827-33. doi:10.1167/iovs.11-9244.

22. Ziegenhagen MW, Schrum S, Zissel G, Zipfel PF, Schlaak M, Müller-Quernheim J. Increased expression of proinflammatory chemokines in bronchoalveolar lavage cells of patients with progressing idiopathic pulmonary fibrosis and sarcoidosis. J Investig Med. 1998;46(5):223-31.

23. Petković TR, Pejcić T, Videnović-Ivanov J, Stoimenov TJ, Janković I, Borovac DN, et al. Tumor necrosis factor alpha gene polymorphism in serbian patients with sarcoidosis. Srp Arh Celok Lek. 2013;141(3-4):169-72.

24. Swider C, Schnittger L, Bogunia-Kubik K, Gerdes J, Flad H, Lange A, et al. TNF-alpha and HLA-DR genotyping as potential prognostic markers in pulmonary sarcoidosis. Eur Cytokine Netw. 1999;10(2):143-6.

25. Paone G, Lucantoni G, Leone A, Graziano P, Gasbarra R, Galluccio G, et al. Human neutrophil peptides stimulate tumor necrosis factor-alpha release by alveolar macrophages from patients with sarcoidosis. Chest. 2009;135(2):586-7.

26. Kempf W, Zollinger T, Sachs M, Ullmer E, Cathomas G, Dirnhofer S, et al. Granulomas are a source of interleukin-33 expression in pulmonary and extrapulmonarysarcoidosis. Hum Pathol. 2014;45(11):2202-10.

27. Martinetti M, Luisetti M, Cuccia M. HLA and sarcoidosis: new pathogenetic insights. Sarcoidosis Vasc Diffuse Lung Dis. 2002;19:83-9.
28. Thio M, Blokhuis BR, Nijkamp FP, Redegeld FA. Free immunoglobulin light chains: a novel target in the therapy of inflammatory diseases. Trends Pharmacol Sci. 2008;29:170-4.

29. Rijnierse A, Redegeld FA, Blokhuis BR, Van der Heijden MW, TeVelde AA, Pronk I, et al. Ig-free light chains play a crucial role in murine mast cell-dependent colitis and are associated with human inflammatory bowel diseases. J Immunol. 2010;185:653-9.

30. Groot Kormelink T, Thio M, Blokhuis BR, Nijkamp FP, Redegeld FA. Atopic and non-atopic allergic disorders: current insights into the possible involvement of free immunoglobulin light chains. Clin Exp Allergy. 2009;39:33-42.

31. Schouten B, Van Esch BC, Van Thuijl AO, Blokhuis BR, Groot Kormelink T, Hofman GA, et al. Contribution of lgE and immunoglobulin free light chain in the allergic reaction to cow's milk proteins. J Allergy Clin Immunol. 2010;125:1308-14.

32. Kraneveld AD, Kool M, Van Houwelingen AH, Roholl P, Solomon A, Postma DS, et al. Elicitation of allergic asthma by immunoglobulin free light chains. Proc Natl Acad Sci U S A. 2005;102:1578-83.

33. van der Heijden M, Kraneveld A, Redegeld F. Free immunoglobulin light chains as target in the treatment of chronic inflammatory diseases. Eur J Pharmacol. 2006;533:319-26.

34. Powe DG, Groot Kormelink T, Sisson M, Blokhuis BJ, Kramer MF, Jones NS, et al. Evidence for the involvement of free light chain immunoglobulins in allergic and nonallergic rhinitis. J Allergy Clin Immunol. 2010;125:139-145.e3.

35. Redegeld FA, Nijkamp FP. Immunoglobulin free light chains and mast cells: pivotal role in T-cell-mediated immune reactions? Trends Immunol. 2003;24:181-5

36. Mehta PD, Cook SD, Troiano RA, Coyle PK. Increased free light chains in the urine from patients with multiple sclerosis. Neurology. 1991;41:540-4.

37. Gottenberg JE, Aucouturier F, Goetz J, Sordet C, Jahn I, Busson M, et al. Serum immunoglobulin free light chain assessment in rheumatoid arthritis and primary Sjogren's syndrome. Ann Rheum Dis. 2007;66:23-7.

38. Gottenberg JE, Miceli-Richard C, Ducot B, Goupille P, Combe B, Mariette X. Markers of B-lymphocyte activation are elevated in patients with early rheumatoid arthritis and correlated with disease activity in the ESPOIR cohort. Arthritis Res Ther. 2009;11:R114.

39. Constantinescu CS, Mehta PD, Rostami AM. Urinary free kappa light chain levels in chronic progressive multiple sclerosis. Pathobiology. 1994;62:29-33.

40. American Thoracic Society, European Respiratory Society. World Association of Sarcoidosis and Other Granulomatous Disorders. Statement on sarcoidosis: joint statement of the American Thoracic Society (ATS), the European Respiratory Society (ERS) and the World Association of Sarcoidosis and Other Granulomatous Disorders (WASOG) adopted by the ATS Board of Directors and by the ERS Executive Committee, February 1999. Am J Respir Crit Care Med. 1999;160:736-55.

41. Group AR. Design of a case control etiologic study of sarcoidosis (ACCESS). J Clin Epidemiol. 1999;52:1173-86.

42. Waksberg J. Sampling methods for random digit dialing. J Am Stat Assoc. 1978;73:40-6.

43. Abe M, Goto T, Kosaka M, Wolfenbarger D, Weiss DT, Solomon A. Differences in kappa to lambda (kappa:lambda) ratios of serum and urinary free light chains. Clin Exp Immunol. 1998;111:457-62.

44. Groot Kormelink T, Tekstra J, Thurlings RM, Boumans MH, Vos K, Tak PP, et al. Decrease in immunoglobulin free light chains in patients with rheumatoidarthritis upon rituximab (anti-CD20) treatment correlates with decrease in disease activity. Ann Rheum Dis. 2010;69:2137-44.

45. Ishimatsu Y, Koyama H, Tomonaga M, Harada T, Nakashima S, Hara A, et al. A Japanese patient with Löfgren's syndrome with an HLA-DR12 allele and review of literature on Japanese patients. Tohoku J Exp Med. 2014;234:137-41.

46. Berlin M, Fogdell-Hahn A, Olerup O, Eklund A, Grunewald J. HLA-DR predicts the prognosis in Scandinavian patients with pulmonary sarcoidosis. Am J RespirCrit Care Med. 1997;156:1601-5.

47. Planck A, Eklund A, Yamaguchi E, Grunewald J. Angiotensin converting enzyme gene polymorphism in relation to HLA-DR in sarcoidosis. J Intern Med. 2002;251:217-22.

48. Papadopoulos Kl, Wassmuth R, Sjöberg K. Sarcoidosis and autoimmunity: evidence of differential associations with HLA class II markers. Int Endocrine Metab. 2006:4:13-8.

49. Hiroe S, Woodhead FA, Tariq A, Grutters JC, Paolo S, Jules MM VB, et al. Sarcoidosis HLA class II genotyping distinguishes differences of clinical phenotype across ethnic groups. Hum Mol Genet. 2010;19(20):4100-11. 
50. Kunikane H, Abe S, Tsuneta Y, Nakayama T, Tajima Y, Misonou J, et al. Role of HLA-DR antigens in Japanese patients with sarcoidosis. Am Rev Respir Dis. 1987;135:688-91

51. Nowack D, Goebel KM. Genetic aspects of sarcoidosis. Arch Intern Med. 1987;147:481-3.

52. Yokoyama T, Kanda T, Kobayashi I, Suzuki T. Serum levels of interleukin-8 as a marker of disease activity in patients with chronic sarcoidosis. J Med. 1995;26(5-6):209-19.

53. Car BD, Meloni F, Luisetti M, Semenzato G, Gialdroni-Grassi G, Walz A. Elevated IL-8 and MCP-1 in the bronchoalveolar lavage fluid of patients with idiopathic pulmonary fibrosis and pulmonary sarcoidosis. Am J RespirCrit Care Med. 1994;149(3 Pt1):655-9.

54. Hackett TL, Holloway R, Holgate ST, Warner JA. Dynamics of pro-inflammatory and anti-inflammatory cytokine release during acute inflammation in chronic obstructive pulmonary disease: an ex vivo study. Respir Res. 2008;9:47.

55. Karimi K, Sarir H, Mortaz E, Smit JJ, Hosseini H, De Kimpe SJ, et al. Toll-like receptor-4 mediates cigarette smoke-induced cytokine production by human macrophages. Respir Res. 2006;7:66.

56. Mortaz E, Rad MV, Johnson M, Raats D, Nijkamp FP, Folkerts G. Salmeterol with fluticasone enhances the suppression of IL-8 release and increases the translocation of glucocorticoid receptor by human neutrophils stimulated with cigarette smoke. J Mol Med. 2008;86:1045-56.

57. Bloom Cl, Graham CM, Berry MP, Rozakeas F, Redford PS, Wang Y, et al. Transcriptional blood signatures distinguish pulmonary tuberculosis, pulmonary sarcoidosis, pneumonias and lung cancers. PLoS One. 2013;8(8):e70630

58. Kunkel SL, Chensue SW, Strieter RM, Lynch JP, Remick DG. Cellular and molecular aspects of granulomatous inflammation. Am J Respir Cell Mol Biol. 1989;1:439-4

59. Tracey KJ. Tumour necrosis factor-alpha. The cytokine handbook. 2nd ed. New York, NY: Academic Press; 1994. p. 289-304.

60. Chensue SW, Warmington KS, Ruth JH, Lincoln P, Kunkel SL. Cytokine function during mycobacterial and schistosomal antigen induced pulmonary granuloma formation: local and regional participation of IFN-alpha, IL-10, and TNF. J Immunol. 1995;154:5969-76.

61. Marques LJ, Zheng L, Poulakis J, Poulakis N, Guzman J, Costabel U. Pentoxifylline inhibits TNF-alpha production from human alveolar macrophages. Am J Respir Crit Care Med. 1999;159:508-11.

62. C. Prior RA. pulmonary sarcoidosis: patterns of cytokines release in vitro. Euro Respir J. 1996:9:47-53

63. Mortaz E, Masjedi MR, Allameh A, Adcock IM. Inflammasome signaling in pathogenesis of lung diseases. Curr Pharm Des. 2012;18(16):2320-8.

64. Lee NS, Barber L, Akula SM, Sigounas G, Kataria YP, Arce S. Disturbed homeostasis and multiple signaling defects in the peripheral blood B-cell compartment of patients with severe chronic sarcoidosis. Clin Vaccine Immunol. 2011:18:1306-16.

65. Sweiss NJ, Lower EE, Mirsaeidi M, Dudek S, Garcia JG, Perkins D, et al. Rituximab in the treatment of refractory pulmonary sarcoidosis. Eur Respir J. 2014;43(5):1525-8

66. Sølling K, Sølling J, Rømer FK. Free light chains of immunoglobulins in serum from patients with rheumatoid arthritis, sarcoidosis, chronic infections and pulmonary cancer. Acta Med Scand. 1981;209(6):473-7.

67. Jolly M, Francis S, Aggarwal R, Mikolaitis R, Niewold T, Chubinskaya S, et al. Serum free light chains, interferon-alpha, and interleukins in systemic lupus erythematosus. Lupus. 2014;23:881-8.

68. Gottenberg JE, Seror R, Miceli-Richard C, Benessiano J, Devauchelle-Pensec $V$, Dieude $P$, et al. Serum levels of beta2-microglobulin and free light chains of immunoglobulins are associated with systemic disease activity in primary Sjogren's syndrome. Data at enrollment in the prospective ASSESS cohort. PLoS One. 2013;8:e59868.

69. Aurélia L, Vincent S, Carole L, Guillaume L, Carine H, Sébastien S, et al. Serum free light chains of immunoglobulins as biomarkers for systemic sclerosis characteristics, activity and severity. Autoimmun Rev. 2014;13:974-80.

\section{Submit your next manuscript to BioMed Central and take full advantage of:}

- Convenient online submission

- Thorough peer review

- No space constraints or color figure charges

- Immediate publication on acceptance

- Inclusion in PubMed, CAS, Scopus and Google Scholar

- Research which is freely available for redistribution 